\title{
Minat Generasi Milenial Terhadap Produk Pembiayaan KPR Bank Syariah
}

\author{
Titik Nurjannah Wijayanti ${ }^{1}$, Farid Hidayat ${ }^{2}$ \\ ${ }^{1}$ Prodi Perbankan Syariah, FEBI UIN Sunan Kalijaga Yogyakarta \\ ${ }^{2}$ Prodi Perbankan Syariah, FEBI UIN Sunan Kalijaga Yogyakarta \\ Email : faridhidayat4449@yahoo.co.id
}

\begin{abstract}
The purpose of this study was to determine the effect of religiosity, promotion, and reputation on millennial geographic interest in the city of Yogyakarta on mortgage financing products at Islamic banks. The population in this study is the entire millennial generation in the city of Yogyakarta in general. The sample in this study was 100 respondents. The research method used is quantitative research methods. The variables of this study use two variables, namely the independent variable and the dependent variable. For independent variables include $\left(X_{1}\right)$ religiosity, $\left(X_{2}\right)$ promotion, $\left(X_{3}\right)$ reputation. For the dependent variable $(y)$ in this study is the interest of millennial generation in using the product Mortgages (KPR) in Islamic banks. This study uses primary data obtained from questionnaires and then analyzed with the help of the SPSS 21 application program. The results of the study show that the variables of religiosity and promotion have a positive and significant influence on the interests of millennial generation using Home Ownership Credit (KPR) products in Islamic banks. While the reputation variable does not affect the interest in the use of Home Ownership Credit (KPR) products in Islamic banks.
\end{abstract}

Keywords : Interest; Religiosity; Promotion; Reputation

\begin{abstract}
Abstrak. Tujuan dari penelitian ini adalah untuk mengetahui pengaruh religiusitas, promosi, dan reputasi terhadap minat geerasi milenial di Kota Yogyakarta terhadap produk pembiayaan KPR pada bank Syariah. Populasi dalam Penelitian ini adalah seluruh generasi milenial di Kota Yogyakarta secara umum. Adapun sampel dalam penelitian ini adalah 100 responden. Metode penelitian yang digunakan adalah metode penelitian kuantitatif. Variabel penelitian ini menggunakan dua variabel yaitu variabel independen dan variabel dependen. Untuk variabel independen $(X)$ meliputi $\left(X_{1}\right)$ religiusitas, $\left(X_{2}\right)$ promosi, $\left(X_{3}\right)$ reputasi. Untuk variabel dependen (y) pada penelitian ini adalah minat generasi milenial dalam menggunakan produk Kredit Pemilikan Rumah (KPR) pada bank syariah. Penelitian ini menggunakan data primer yang diperoleh dari kuesioner dan kemudian dianalisis dengan bantuan program aplikasi SPSS 21. Hasil penelitian menunjukan bahwa variabel religiusitas dan promosi berpengaruh postif dan signifikan terhadap minat generasi milenial menggunakan produk Kredit Pemilikan Rumah (KPR) pada bank syariah. Sedangkan variabel reputasi tidak berpengaruh terhadap terhadap minat dalam penggunaan produk Kredit Pemilikan Rumah (KPR) pada bank syariah.
\end{abstract}

Kata Kunci : Minat; Religiusitas; Promosi; Reputasi 


\section{PENDAHULUAN}

Kebutuhan manusia menurut intensitas kebutuhannya dibedakan menjadi tiga yaitu kebutuhan primer, kebutuhan sekunder, dan kebutuhan tersier. Kebutuhan primer manusia terdiri dari tiga macam yaitu kebutuhan makan, kebutuhan sandang, dan kebutuhan papan (Hidayat, 2015 :2).

Salah satu permasalahan utama yang masih dihadapi oleh masyarakat di Indonesia adalah mengenai ketersediaan rumah, yaitu kesenjangan antara jumlah rumah yang terbangun dengan jumlah rumah yang dibutuhkan oleh masyarakat (Hudiyanto, dkk. 2017). Sehingga menyebabkan harga rumah semakin melambung, yang mengakibatkan sulit membeli rumah secara tunai (Alexander, 2015). Direktur Retail Banking Bank Mandiri Donusuwa Simatupang mengatakan bahwa masih ada 11 juta orang yang membutuhkan rumah, terutama generasi milenial (Arief, 2018).

Menurut Edy Muhammad, kepala Bappeda Kota Yogyakarta pada tahun 2015 rumah tinggal yang ada di Kota Yogyakarta tercatat 92.965 unit, dengan kebutuhan hunian masyarakat mencapai 101.526 unit. Secara teoritis, kebutuhan hunian masyarakat Yogyakarta masih kekurangan 8.560 rumah (Wid, 2016).

Generasi milenial adalah mereka yang dilahirkan antara tahun 1980 sampai dengan 2000. Menurut Survei Sosial Ekonomi Nasional (SUSENAS) 2017, jumlah generasi milenial mencapai sekitar 88 juta jiwa atau 33,75\% dari total penduduk Indonesia. Generasi milenial di Kota Yogyakarta berjumlah 129.455 jiwa atau 31,27\% dari total penduduk Kota Yogyakarta (Setda, 2018). Konsep generasi milenial Indonesia adalah penduduk Indonesia yang lahir antara tahun 1980-2000 (Budiati, dkk. 2018). Hal ini berarti milenial adalah generasi muda yang berumur 19-39 pada tahun 2019.

Generasi milenial dianggap sebagai sasaran pasar properti di sejumlah kawasan berkembang. Pasalnya, kalangan milenial yang mulai mendapatkan kerja, belum memiliki rumah, serta baru menjalani kehidupan mandiri sehingga berpotensi untuk membeli rumah pertama dengan cara mencicil/mengajukan pembiayaan Kredit Pemilikan Rumah (KPR) di lembaga keuangan seperti bank syariah (SINDOnews 2018). Sedangkan jumlah penduduk D.I Yogyakarta tahun 2016 berdasarkan data BPS ter-update pada tanggal 29 Januari 2018 sebanyak 3.720 .912 jiwa. Untuk jumlah penduduk Kota Yogyakarta berjumlah 417.744 jiwa (DIY n.d.).

Berdasarkan penelitian yang dilakukan oleh (Ismail, Azmi, and Thurasamy, 2014) dengan judul "Selection Criteria For Islamic Home Finance in Malaysia" dan hasil yang menunjukkan bahwa reputasi, kualitas layanan, agama, iklan media dan pengaruh sosial menjadi faktor penting yang mempengaruhi pemilihan pembiayaan rumah Islam.

Penelitian yang dilakukan oleh (Alam et al. 2012) dengan judul "Is Religiosity an Important Factor in Influencing the Intention to Undertake Islamic Home Financing in Klang Valley?"dan hasil yang menunjukkan bahwa religiusitas, sikap dan perilaku memiliki pengaruh signifikan terhadap niatPembiayaan secara rumah Islami di kalangan Muslim di Lembah Klang.

Dengan melihat perkembangan ekonomi di Daerah Istimewa Yogyakarta, dimana sebagian besar aktifitas perekonomiannya terpusat di Kota Yogyakarta, hal ini dapat mendorong adanya peningkatan harga rumah dan tanah, karena sebagian lahan di wilayah perkotaan menjadi incaran para investor untuk mengembangkan bisnisnya seperti, hotel, rumah makan, mall, dan lain-lain. Sehingga lahan di wilayah perkotaan untuk pemukinan semakin berkurang (Saroh, 2016).

Berdasarkan hal tersebut, penelitian ini menggunakan model penelitian yang telah dikembangkan dari beberapa penelitian yang telah ada dengan mengambil variabel-variabel dari penelitian sebelumnya. Variabel-variabel tersebut adalah religiusitas, promosi, dan reputasi bank sebagai dasar yang mempengaruhi generasi millennials di Kota Yogyakarta terhadap minat menggunakan produk Kredit Pemilikan Rumah pada Bank Syariah. 


\section{METODE PENELITIAN}

Penelitian ini merupakan jenis penelitian lapangan dengan pendekatan kuantitatif, penelitian ini menggunakan tiga teknik pengumpulan data, yaitu kuesioner, wawancara, dan studi pustaka. Jumlah sampel dalam penelitian ini sebanyak 100 orang dan menggunakan metode purposive sampling, sampel yang digunakan mempunyai kriteria sebagai berikut :

1. Responden penelitian merupakan generasi milenial yaitu seseorang yang memiliki umur 19-39 tahun pada tahun 2019.

2. Responden merupakan generasi milenial yang berada di wilayah kota Yogyakarta.

3. Responden merupakan generasi milenial yang belum memiliki rumah sendiri (masih tinggal bersama orang tua/kos/kontrak).

Penelitian ini akan dianalisis dengan menggunakan analisis deskriptif, analisis kuantitatif dan analisis regresi linier berganda. dalam analisis kuantitatif akan dilakukan uji normalitas dan uji asumsi klasik, kemudian dalam analisis regresi linier berganda akan dilakukan uji signifikan simultan (uji statistik f), koefisien determinasi $\left(r^{2}\right)$ dan uji signifikan parameter individual (uji statistik $t$ ).

\section{HASIL DAN PEMBAHASAN}

\section{Waktu dan Tempat Penelitan}

Penelitian ini dilaksanakan selama bulan Mei hingga bulan Juni 2019. Penelitian ini berlokasi di Kota Yogyakarta, Daerah Istimewa Yogyakarta. Lebih tepatnya di jalan muja-muju, jalan hibrida, jalan gejayan, jalan solo, jalan kusumanegara, jalan malioboro, jalan colombo, jalan veteran, jalan batikan, dII.

\section{Uji Asumsi Klasik}

Dalam uji asumsi klasik terdapat beberapa uji, yaitu :

\subsection{Uji Normalitas}

Uji Normalitas bertujuan untuk melihat apakah data residual terdistribusi normal atau tidak. Data yang baik dan layak digunakan dalam penelitian adalah data yang berdistribusi normal (Sujarweni, 2007: 55). Jika residual data tidak terdistribusi normal maka kesimpulan statistik menjadi tidak valid atau bias.

Uji normalitas dapat menggunakan uji Kolmogorov-Smirnov, apabila nilai Asymp Sif (2-tailed) lebih besar dari $a=5 \%$ atau 0,05 , maka dapat disimpulkan bahwa residual pada model regresi mengikuti distirbusi normal (Umar, 2013: 181).atau dengan kriteria pengambilan keputusan seperti dibawah ini (Sujarweni, $2007: 58$ ).

Jika Sig. $>0.05$, maka data berdistribusi normal

Jika Sig. $<0.05$, maka data tidak berdistribusi normal

Berdasarkan penghitungan One-Sampel Kolmogorov-Smirnov Test diperoleh angka probabilitas atau Asymp. Sig. (2-tailed) sebesar 0,199. Dengan demikian nilai sig. 0,199 $\geq 0,05$, maka data dapat dikatakan berdistribusi normal.

\subsection{Uji Multikolinearitas}

Uji Multikolinearitas bertujuan untuk menguji apakah dalam model regresi ditemukan adanya korelasi yang tinggi atau sempurna antar variabel independen. Jika hubungan itu mendekati 1 artinya hubungannya mendekati sempurna. Model regresi yang baik seharusnya tidak terjadi korelasi antara variabel independen. Untuk mendeteksi ada atau tidaknya multikolinearitas di dalam model regresi dapat dilihat dari nilai tolerance maupun dari nilai Variance Inflation Factor (VIF) (Ghozali, 2014 : 105106). 
Umumnya penilaian yang sering dilakukan untuk mengetahui adanya multikoleniaritas adalah : Nilai Tolerance $\leq 0,10$, maka jika Tolerance $>0,10$ dikatakan tidak ada multikolenearitas.

Nilai VIF $\geq 10$, maka jika VIF $<10$ dikatakan tidak ada multikolenearitas.

Hasil perhitungan nilai tolerance menunjukkan tidak ada variabel independen yang memiliki nilai tolerance kurang dari 0.010 dan nilai Variance Inflation Factor (VIF) juga menunjukkan tidak ada data yang lebih dari 10 sehingga dapat dikatakan tidak terjadi multikolonieritas.

\subsection{Uji Heteroskedastisitas}

Uji Heteroskedastisitas bertujuan untuk menguji apakah dalam model terjadi ketidaksamaan variance dari residual satu pengamatan ke pengamatan yang lain (Ghozali, 2011 :87). Ada beberapa cara untuk mengetahui ada atau tidaknya heteroskedastisitas : melihat grafik plot (ZRED dan SRESID), Uji Park, Uji Glejser, dan Uji White. Kriteria yang digunakan untuk mengetahui terjadi atau tidaknya heteroskedastisitas dengan menggunakan signifikansi. Apabila koefisien signifikansi lebih besar dari 0,05 maka dapat dinyatakan tidak terjadi heteroskedastisitas.

Dari hasil uji heteroskedastisitas yang menggunakan uji park diperoleh nilai signifikansi variabel Religiusitas $/ X_{1}(0,365)$, variabel Promosi $/ X_{2}(0,567)$, dan Variabel Reputasi $/ X_{3}(0,724)$, lebih besar dari alpha 0,05. Maka dapat disimpulkan bahwa variabel penelitian ini lolos uji heteroskedastisitas.

\section{Regresi Linier Berganda}

Analisis regresi adalah studi bagaimana suatu variabel yaitu variabel dependen dipengaruhi oleh satu atau lebih variabel independen (Widarjono, 2010 : 7). Dalam penelitian ini, peneliti menggunakan analisis regresi linier berganda karena jumlah variabel independen lebih dari satu. Analisis regresi berganda digunakan untuk mengetahui seberapa besar pengaruh variabel bebas (independent) yaitu: religiusitas $(X 1)$, promosi $(X 2)$, reputasi $(X 3)$ terhadap variabel terikat (dependent) minat generasi milenial menggunakan produk KPR pada Bank Syariah (Y).

Tabel 1

Hasil Uji Regresi Linear Berganda Coefficients ${ }^{a}$

\begin{tabular}{|c|c|c|c|c|c|c|}
\hline \multirow{2}{*}{\multicolumn{2}{|c|}{ Model }} & \multicolumn{2}{|c|}{$\begin{array}{l}\text { Unstandardized } \\
\text { Coefficients }\end{array}$} & \multirow{2}{*}{$\begin{array}{c}\text { Standardized } \\
\text { Coefficients }\end{array}$} & \multirow[t]{2}{*}{$\mathrm{T}$} & \multirow[t]{2}{*}{ Sig. } \\
\hline & & $B$ & Std. Error & & & \\
\hline \multirow{4}{*}{1} & (Constant) & 1.376 & 1.557 & & .884 & .379 \\
\hline & RELIGIUSITAS & .186 & .080 & .231 & 2.327 & .022 \\
\hline & PROMOSI & .317 & .111 & .305 & 2.857 & .005 \\
\hline & REPUTASI & .043 & .114 & .042 & .375 & .709 \\
\hline
\end{tabular}

Data diolah tahun 2019 menggunakan SPSS 21

Dari hasil regresi di atas dapat diketahui persamaan regresi berganda sebagai berikut : $\mathrm{Y}=$ $1,376+0,186 X_{1}+0,317 X_{2}+0,043 X_{3}$

a. Konstanta

Hasil koefisisen regresi menunjukkan nilai koefisien konstanta adalah sebesar 1,376 mempunyai arti bahwa jika minat akan konstanta sebesar 1,376.

b. Religiusitas $\left(X_{1}\right)$

Besarnya nilai koefisien regresi promosi sebesar 0,186 dan bernilai positif dengan signifikansi 0,022 < 0,05 , sehingga variabel religiusitas berpengaruh positif dan signifikan terhadap minat. Hal ini 
menunjukkan bahwa jika religiusitas meningkat sebesar 1 satuan, maka akan terjadi peningkatan pada minat sebesar 0,186 dengan asumsi variabel lainnya tetap atau konstan.

c. Promosi (X2)

Besarnya nilai koefisien regresi promosi sebesar 0,317 dan bernilai positif dengan signifikansi 0,005 < 0,05 , sehingga variabel promosi berpengaruh terhadap minat. Hal ini menunjukkan bahwa jika promosi meningkat sebesar 1 satuan, maka akan terjadi peningkatan pada minat sebesar 0,317 dengan asumsi variabel lainnya tatap atau konstan.

d. Reputasi (X3)

Besarnya nilai koefisien regresi reputasi sebesar 0,043 dan bernilai positif dengan signifikansi 0,709 > 0,05 , sehingga variabel reputasi tidak berpengaruh terhadap minat. Hal ini menunjukkan bahwa berapapun kenaikn pada variabel reputasi tidak akan berpengaruh terhadap minat.

\section{Uji Hipotesis}

\subsection{Uji Signifikan Simultan (Uji Statistik F)}

Uji $\mathrm{F}$ digunakan untuk melihat apakah variabel bebas mampu secara bersama-sama mempengaruhi variabel terikat. Untuk mengetahui pengaruh variabel independen secara bersamasama terhadap variabel dependen dengan melihat pada tabel anova, kriteria pengujiannya adalah nilai $\mathrm{F}$ hitung $>\mathrm{F}$ tabel atau nilai probabilitas signifikansi $<0,05$. Jika nilai $\mathrm{F}$ hitung $>\mathrm{F}$ tabel atau nilai probabilitas signifikansi $<0,05$ maka dapat dikatakan variable independen secara bersama-sama mempengaruhi variabel dependen. Uji $\mathrm{F}$ ini bisa dijelaskan dengan menggunakan analisis varian (anova) seperti pada tabel berikut ini :

\section{Tabel 2}

\section{Hasil Uji Simultan (Uji F)}

\begin{tabular}{|c|c|c|c|c|c|c|}
\hline \multicolumn{7}{|c|}{ ANOVA $^{a}$} \\
\hline & & Sum of Squares & $\mathrm{Df}$ & $\begin{array}{l}\text { Mean } \\
\text { Square }\end{array}$ & $\mathrm{F}$ & Sig. \\
\hline \multirow{3}{*}{1} & Regression & 44.227 & 3 & 14.742 & 7.950 & $.000^{\mathrm{b}}$ \\
\hline & Residual & 178.013 & 96 & 1.854 & & \\
\hline & Total & 222.240 & 99 & & & \\
\hline
\end{tabular}

a. Dependent Variable: MINAT

b. Predictors: (Constant), REPUTASI, RELIGIUSITAS, PROMOSI

Sumber data diolah tahun 2019, menggunakan SPSS 21

Dari tabel diatas dapat dilihat bahwa nilai $F_{\text {hitung }}$ yang dihasilkan sebesar 14,742 dengan tingkat signifikansi 0,000 . Karena probabilitas jauh lebih kecil dari taraf signifikansi $5 \%$ atau 0,05 $(0,000<0,05)$. Dengan demikian dapat disimpulkan bahwa model regresi dapat digunakan untuk memprediksi minat atau dapat dikatakan bahwa religiusitas, promosi, dan reputasi secara bersamasama berpengaruh terhadap minat

\subsection{Koefisien Determinasi $\left(R^{2}\right)$}

Koefisien determinasi $\left(R^{2}\right)$ adalah ukuran untuk mengetahui kesesuaian atau ketepatan hubungan antara variabel independen dengan variabel dependen. Nilai koefisien determinasi dalam penghitungan SPSS ditunjukkan pada nilai model summary pada kolom adjusted $\mathrm{R}$ square. Besarnya koefisien determinasi adalah nol sampai satu. Semakin mendekati satu maka semakin besar pengaruh semua variabel independen terhadap variabel dependen. Sebaliknya, semakin mendekati nol maka semakin kecil pengaruh semua variabel independen terhadap variabel dependen. Berikut adalah hasil uji koefiien determinasi : 
Tabel 3

Hasil Uji Koefisien Determinasi (R2)

Model Summary

\begin{tabular}{|l|r|r|r|r|}
\hline Model & R & R Square & \multicolumn{1}{c|}{$\begin{array}{c}\text { Adjusted R } \\
\text { Square }\end{array}$} & $\begin{array}{c}\text { Std. Error of } \\
\text { the Estimate }\end{array}$ \\
\hline 1 & $.446^{\mathrm{a}}$ & .199 & .174 & 1.362 \\
\hline
\end{tabular}

a. Predictors: (Constant), REPUTASI, RELIGIUSITAS, PROMOSI

Sumber : data diolah tahun 2019, dengan SPSS 21

Berdasarkan tabel di atas dapat diketahui nilai adjusted $R^{2}$ sebesar 0,174. Hal ini menunjukkan bahwa minat masyarakat dapat dijelaskan oleh religiusitas, promosi, dan reputasi sebesar $17,4 \%$. Sedangkan sisanya yaitu $82,6 \%$ (100\% - 17,4\%) dijelaskan oleh variabel lain diluar penelitian.

\subsection{Uji Signifikan Parameter Individual (Uji Statistik t)}

Uji t pada dasarnya menunjukkan seberapa besar pengaruh satu variabel penjelas atau independen secara individual dalam menerangkan variasi variabel dependen (Ghozali, 2014 : 98-99). Dengan melihat pada tabel coeficien, kriteria pengujiannya adalah nilai $t$ hitung $>t$ tabel atau nilai probabilitas signifikansi $<0,05$. Jika nilai $t$ hitung $>t$ tabel atau nilai probabilitas signifikansi $<0,05$ maka dapat dikatakan variabel independen secara individual berpengaruh terhadap variabel.

Tabel 4

Hasil Uji parsial (uji t)

Coefficients $^{\mathrm{a}}$

\begin{tabular}{|c|c|c|c|c|c|c|}
\hline \multirow{2}{*}{\multicolumn{2}{|c|}{ Model }} & \multicolumn{2}{|c|}{$\begin{array}{l}\text { Unstandardized } \\
\text { Coefficients }\end{array}$} & \multirow{2}{*}{$\begin{array}{c}\text { Standardize } \\
\text { d } \\
\text { Coefficients }\end{array}$} & \multirow[t]{2}{*}{ T } & \multirow[t]{2}{*}{ Sig. } \\
\hline & & $B$ & Std. Error & & & \\
\hline \multirow{4}{*}{1} & (Constant & 1.376 & 1.557 & & .884 & .379 \\
\hline & $\begin{array}{l}\text { RELIGIUSI } \\
\text { TAS }\end{array}$ & .186 & .080 & .231 & 2.327 & .022 \\
\hline & PROMOSI & .317 & .111 & .305 & 2.857 & .005 \\
\hline & REPUTASI & .043 & .114 & .042 & .375 & .709 \\
\hline
\end{tabular}

a. Dependent Variable: MINAT

Data diolah tahun 2019, menggunakan SPSS 21 
Berdasarkan data diatas dapat dianalisis sebagai berikut :

1) Pengujian Hipotesis Pertama

Pengujian Hipotesis Pertama digunakan untuk menguji pengaruh variabel religiusitas terhadap minat generasi milenial menggunakan produk KPR pada Bank Syariah. Hipotesis yang dibangun yaitu :

Berdasarkan tabel diatas variabel relisiusitas memiliki nilai signifikansi $0,022<0,05$. Maka menerima $\mathrm{Ha}$, hal ini menunjukkan bahwa religiusitas berpengaruh positif terhadap minat generasi milenial menggunakan produk KPR pada Bank Syariah, sehingga dapat dikatakan hipotesis pertama diterima.

2) Pengujian Hipotesis Kedua

Pengujian hipotesis kedua digunakan untuk menguji pengaruh variabel promosi terhadap minat generasi milenial menggunakan produk KPR pada Bank Syariah. Hipotesis yang dibangun yaitu :

Berdasarkan tabel diatas dapat diketahui bahwa variabel promosi memiliki nilai signifikansi 0,005 $<0,05$. Maka menerima $\mathrm{Ha}$, hal ini menunjukkan bahwa promosi berpengaruh positif terhadap minat generasi milenial mengajukan pembiayaan KPR pada Bank Syariah, sehingga dapat dikatakan hipotesis kedua diterima.

3) Pengujian Hipotesis Ketiga

Pengujian hipotesis ketiga digunakan untuk menguji pengaruh variabel reputasi terhadap minat generasi milenial menggunakan produk KPR pada Bank Syariah. Hipotesis yang dibangun yaitu :

Berdasarkan tabel diatas dapat diketahui bahwa variabel promosi memiliki nilai signifikansi $0,702>0,05$. Maka menerima HO, hal ini menunjukkan bahwa reputasi tidak berpengaruh positif terhadap minat generasi milenial mengajukan pembiayaan KPR pada Bank Syariah, sehingga dapat dikatakan hipotesis ketiga ditolak.

\section{Pembahasan}

a. Pengaruh Religiusitas Terhadap Minat Generasi Milenial Menggunakan Produk KPR pada Bank Syariah

Jawaban responden pada variabel religiusitas yaitu sebanyak $52,8 \%$ masyarakat menjawab setuju, 42,2\% menjawab sangat setuju, 4,6\% menjawab tidak setuju, dan 0,4\% menjawab sangat tidak setuju. Maka dari itu penulis menyimpulkan bahwa $95 \% \quad(52,8 \%+42,2 \%)$ jawaban responden menganggap bahwasanya religiusitas yang dilakukan oleh Bank Syariah dapat menimbulkan minat yang tinggi.

Jika nilai $\mathrm{t}$ hitung $>\mathrm{t}$ tabel dan sig. $<0,05$ maka $\mathrm{H}_{1}$ diterima, sebaliknya apabila $\mathrm{t}$ hitung $<\mathrm{t}$ tabel dan sig. $>0,05$ maka $\mathrm{H}_{1}$ ditolak. Berdasarkan hasil olah data statistik menunjukkan nilai signifikansi variabel religiusitas lebih kecil alpha yaitu sebesar 0,022 $<0,05$. Dengan demikian penelitian ini berhasil menerima hipotesis pertama $\left(\mathrm{H}_{1}\right)$. Dapat disimpulkan bahwa religiusitas berpengaruh positif dan signifikan terhadap minat generasi milenial menggunakan produk KPR pada Bank Syariah.

Hasil Penelitian ini sejalan dengan penelitian yang dilakukan oleh (Laili, 2013) yang berjudul "Pengaruh Faktor Agama Terhadap Minat Nasabah Memilih Produk Pembiayaan Kepemilikan Rumah (KPR) Di BTN (Bank Tabungan Negara) Syari'ah Cabang Semarang". Hasil penelitian menunjukkan bahwa terdapat pengaruh positif dan signifikan antara faktor agama terhadap minat nasabah memilih produk Pembiayaan Kepemilikan Rumah (KPR) Di BTN (Bank Tabungan 
Negara) Syari'ah cabang Semarang. Selanjutnya penelitian yang dilakukan oleh (Ali et al. 2017) dengan judul "Islamic home financing in Pakistan: A SEM based approach using modified TPB model". Hasil penelitian menunjukkan bahwa religiusitas memiliki hubungan positif dengan niat pelanggan untuk menggunakan rumah Islami pembiayaan di Pakistan.

Hasil wawancara yang dilakukan dengan Faqih, salah seorang generasi milenial di Kota Yogyakarta, mengatakan bahwa lebih baik menggunakan bank syariah karena sepertinya lebih adil, bebas dari riba, dan ingin menjauhi secara bertahap produk-produk bank yang saya ketahui ada riba didalamnya.

\section{b. Pengaruh Promosi Terhadap Minat Generasi Milenial Menggunakan Produk Pembiayaan KPR pada Bank Syariah}

Berdasarkan nilai $\mathrm{t}$ hitung $>\mathrm{t}$ tabel dan sig. $<0,05$ maka $\mathrm{H}_{2}$ diterima, sebaliknya apabila $\mathrm{t}$ hitung < $\mathrm{t}$ tabel dan sig. $>0,05$ maka $\mathrm{H}_{2}$ ditolak. Berdasarkan hasil olah data statistik menunjukkan nilai signifikansi variabel promosi lebih kecil alpha yaitu sebesar 0,005 0,05. Dengan demikian penelitian ini berhasil menerima hipotesis kedua $\left(\mathrm{H}_{2}\right)$. Dapat disimpulkan bahwa promosi berpengaruh positif dan signifikan terhadap minat generasi milenial di Yogyakarta menggunakan produk KPR pada Bank Syariah.

Jawaban responden pada variabel promosi yaitu sebanyak $0,75 \%$ masyarakat menjawab setuju, 14,75\% menjawab sangat setuju, 74\% menjawab tidak setuju, dan 10,5\% menjawab sangat tidak setuju. Maka dari itu penulis menyimpulkan bahwa $84,5 \%(74 \%+10,5 \%)$ jawaban responden menganggap bahwasanya religiusitas yang dilakukan oleh Bank Syariah dapat menimbulkan minat yang tinggi.

Hasil wawancara dengan Dini, promosi bank syariah cukup menarik, namun sayang sekali saya hanya mengetahui promosi produk dan jasa bank syariah saat saya pergi ke bank syariah terkait dan kadang melalui smarphone saya. Sedangkan hasil wawancara dengan Rizky, menurutnya bank syariah dalam mempromosikan produknya sudah dapat menarik minat, namun harus lebih giat lagi dalam melakukan promosi di mana saja, melalui media apa saja agar semakin banyak lagi masyarakat yang mengetahui mengenai bank syariah secara luas.

\section{c. Pengaruh Reputasi Terhadap Minat Generasi Milenial Menggunakan Produk KPR pada Bank Syariah}

Jawaban responden pada variabel reputasi yaitu sebanyak $80,5 \%$ masyarakat menjawab setuju, 13,25\% menjawab sangat setuju, 5,5\% menjawab tidak setuju, dan 0,75\% menjawab sangat tidak setuju. Maka dari itu penulis menyimpulkan bahwa 93,75\% (80,5\% + 13,25\%) jawaban responden menganggap bahwasanya reputasi yang dilakukan oleh Bank Syariah dapat menimbulkan minat yang tinggi. Namun setelah di analisis menggunakan bantuan alat analisis SPSS 21 menyatakan bahwa reputasi tidak mempengaruhi minat generasi milenial di Kota Yogyakarta terhadap produk pembiayaan KPR pada bank Syariah.

Berdasarkan nilai $\mathrm{t}$ hitung $>\mathrm{t}$ tabel dan sig. $<0,05$ maka $\mathrm{H}_{2}$ diterima, sebaliknya apabila $\mathrm{t}$ hitung $<\mathrm{t}$ tabel dan sig. $>0,05$ maka $\mathrm{H}_{2}$ ditolak. Berdasarkan hasil olah data statistik menunjukkan nilai signifikansi variabel reputasi lebih besar dari alpha yaitu sebesar 0,709>0,05. Dengan demikian penelitian ini tidak berhasil menerima hipotesis ketiga $\left(\mathrm{H}_{3}\right)$. Dapat disimpulkan bahwa reputasi tidak berpengaruh positif dan signifikan terhadap minat generasi milenial di Kota Yogyakarta menggunakan produk KPR pada Bank Syariah. 
berdasarkan wawancara dengan Rizky, seorang generasi milenial di Kota Yogyakarta penulis mendapatkan inofrmasi bahwa sebenarnya kualitas barang dan jasa yang diberikan oleh bank syariah bisa dikatakan mampu bersaing dengan bank konvensional namun, jika bertransaksi dalam bank syariah saya membandingkan dari segi harganya yang lebih mahal. Mengenai karyawan yang ada di perbankan syariah saya berpendapat sama dengan karyawan pada bank konvensional dari segi pakaian yang digunakan kurang mencerminkan kesyar'ian seorang muslim.

Wawancara selanjutnya dengan Fadhila, seorang generasi milenial di kota Yogyakarta. Fadhila adalah salah satu nasabah dari suatu bank syariah. Menurutnya reputasi bank syariah cukup bagus, namun kurang menimbulkan minat untuk bertransaksi di bank syariah, karena menurut pengalamannya seorang Costumer Service terlihat masih ragu/kebingungan saat menjelaskan mengenai masalah akad pada bank syariah sendiri.

\section{KESIMPULAN}

Berdasarkan analisis data dan pembahasan tersebut, maka dapat diperoleh kesimpulan sebagai berikut:

1. Religiusitas dan promosi berpengaruh positif dan signifikan terhadap minat generasi milenial di Kota Yogyakarta menggunakan produk KPR pada Bank Syariah. Hal ini menunjukkan bahwa dengan semakin tinggi Religiusitas dan promosi, maka akan meningkatkan minat generasi milenial untuk menggunakan produk KPR pada Bank Syariah.

2. Reputasi tidak berpengaruh terhadap minat generasi milenial di Kota Yogyakarta untuk menggunakan produk KPR pada Bank Syariah. Hal ini menunjukkan bahwa reputasi tidak berpengaruh terhadap minat generasi milenial di Kota Yogyakarta untuk menggunakan produk KPR pada Bank Syariah.

\section{DAFTAR PUSTAKA}

Alam, Syed Shah et al. 2014. "Is Religiosity an Important Factor in Influencing the Intention to Undertake Islamic Home Financing in Klang Valley?" World Applied Sciences Journal 19(7): 1030-41.

Alexander, Hilda B. 2015. "Ini Penyebab Harga Rumah Terus Melejit." Kompas.com: 1. https://properti.kompas.com/read/2015/02/22/190000721/Ini.Penyebab.Harga.Rumah.Terus. Melejit.

Arief, Andi M. 2018. "Mandiri Luncurkan KPR Khusus Milenial, Cicilan Mulai Rp1,5 Juta Per Bulan."https://finansial.bisnis.com/read/20181010/90/847985/mandiri-luncurkan-kpr-khususmilenial-cicilan-mulai-rp15-juta-per-bulan.

Budiati, Indah et al. 2018. "Profil Generasi Milenial Indonesia." : 1-153. www.freepik.com.

DIY, BPS Provinsi. Jumlah Penduduk Menurut Kabupaten/Kota Di D.I Yogyakarta (Jiwa). https://yogyakarta.bps.go.id/subject/12/kependudukan.html\#subjekViewTab3.

Ghozali, Imam. 2011. Aplikasi Analisis Multivariate Dengan Program IBM SPSS 19. Semarang: Badan Penerbit UNDIP. 
---. 2014. Structural Equation Modeling, Metode Alternatif Dengan Partial Least Square (PLS). Semarang: Badan Penerbit Universitas Dipenogoro.

Hidayat, Rahmat. 2015. "Beranda IPS." Kita Punya. https://www.kitapunya.net/2015/07/macammacam-kebutuhan-manusia.html.

Hudiyanto; Sarwin, Kiko Napitupulu; Robby, Kurniawan; Aryanti, Dwi Rachmawati; Willy, N. Ichwan. 2017. "Kajian Perlindungan Konsumen Sektor Jasa Keuangan : Kredit Pemilikan Rumah ( KPR )." $\begin{array}{lll}\text { Otoritas Jasa Keuangan: 12-20. } & \text {. }\end{array}$ https://konsumen.ojk.go.id/MinisiteDPLK/images/upload/201807131448401. KPR.PDF.

Ismail, Shafinar, Farah Azmi, and Ramayah Thurasamy. 2014. "Selection Criteria for Islamic Home." International Journal of Business and Society 15(1): 97-110.

Istijanto. 2010. Riset Sumber Daya Manusia: Cara Praktis Mengukur Stres, Kepuasan Kerja, Komitmen, Loyalitas, Motivasi Kerja \& Aspek-Aspek Kerja Karyawan Lainnya. Jakarta: PT Gramedia Pustaka Utama.

Rinaswitas, 2017. Nur Ghufron dan Rini. Teori-Teori Psikologi. Yogyakarta: AR-RUZ Media.

Santoso, Singgih. Buku Latihan SPSS Parametrik. Jakarta: Gramedia, 2001.

Saroh, Mutaya, 2016. "Yogya, Rumah, Dan Ketimpangan Kelas." Tirto.id. https://tirto.id/yogyarumah-dan-ketimpangan-kelas-bCQo.

Setda, Biro Tata Pemerintahan. (2018). https://kependudukan.jogjaprov.go.id/olah.php?module=statistik\&periode=11\&jenisdata=pend uduk\&berdasarkan=golonganusia\&rentang=1\&prop=34\&kab=00, 2018.

SINDOnews. 2018. "Milenial Dan Kebutuhan Perumahan." Koran Sindo: 1-2. https://nasional.sindonews.com/read/1285967/18/milenial-dan-kebutuhan-perumahan1519861043.

Sujarweni, V Wiratna. 2007. Belajar Mudah Menggunakan SPSS. Yogyakarta: Ardana Media.

Siamat, Dahlan, 2005, Manajemen Lembaga Keuangan, Edisi Keempat, Badan Penerbit Fakultas Ekonomi Universitas Indonesia, Jakarta. Subaweh, Imam. 2008. Analisis Perbandingan Kinerja Keuangan Bank Syariah dan Bank Konvensional Periode 2003-2007. Jurnal Ilmiah Ekonomi Bisnis.Vol.13, No.2. Sudarsono, Heri. 2009. Dampak Krisis Keuangan Global terhadap Perbankan di Indonesia: Perbandingan antara Bank Konvensional dan Bank Syariah. Jurnal Ekonomi Islam. Vol III, No. 1. Sutawijaya, Adrian dan Etty Puji Lestari. 2009. Efisiensi Teknik Perbankan Indonesia Pascakrisis Ekonomi: Sebuah Studi Empiris Penerapan Model DEA. Jurnal Ekonomi Pembangunan. Vol 10, No.1. Yudhistira, Donsyah. 2003. Efficiency in Islamic Banking an Empirical Analysis of 18 Banks." Proceeding of Islamic Conference on Islamic Banking. Jakarta. Wid. 2016. "Lahan Permukiman Di Kota Yogyakarta Makin Berkurang Artikel Ini Telah Tayang Di Tribunjogja.Com Dengan Judul Lahan Permukiman Di Kota Yogyakarta Makin Berkurang. https://jogja.tribunnews.com/2016/09/26/lahan-permukiman-di-kota-yogyakarta-makinberkurang. 
Widarjono, Agus, 2010. Analisis Statitiska Multivariat Terapan: Dengan Progam SPSS, AMOS, Dan SMARTPLS. Yogyakarta: UPP STIM YKPN.

Yogyakarta, Pemerintah Kota. KONDISI GEOGRAFIS KOTA YOGYAKARTA. https://www.jogjakota.go.id/pages/geografis.

Yudhistira, Donsyah. 2003. Efficiency in Islamic Banking an Empirical Analysis of 18 Banks." Proceeding of Islamic Conference on Islamic Banking. Jakarta. 